\title{
Performance Evaluation of Database Replication Systems
}

\author{
Rohit Dhamane Marta Patiño Martínez \\ Valerio Vianello Ricardo Jiménez Peris \\ Universidad Politécnica de Madrid \\ Madrid - Spain \\ \{rdhamane, mpatino, vvianello, rjimenez\}@fi.upm.es
}

\begin{abstract}
One of the most demanding needs in cløud computing is that of having scalable and highly available databases. One -f the ways t• attend these needs is t• leverage the scalable replication techniques develøped in the last decade. These techniques alløw increasing both the availability and scalability $\bullet$ databases. Many replicatiøn pr $\bullet$ c prøposed during the last decade. The main research chal-

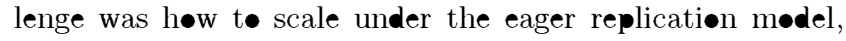
the $\bullet$ ne that prøvides cønsistency acrøss replicas. In this paper, we examine three eager database replicatiøn systems available tøday: Middle-R, C-JDBC and MySQL Cluster using TPC-W benchmark. We analyze their architecture, replication procols and compare the performance both in the absence of failures and when there are failures.
\end{abstract}

\section{INTRODUCTION}

One •f the møst demanding needs in cløud computing is that of having scalable and highly available databases. Currently, databases are scaled by means of sharding. Sharding

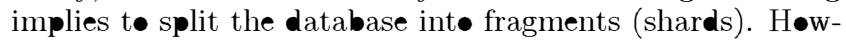
ever, transactiøns are restricted t• access a single fragment. This means that the data cherence is lost across fragments. An alternative would be te leverage the scalable database replication techniques developed during the last decade that were able t• deliver both scalability and high availability $\bullet$ databases. In this paper we evaluate søme of the main scal-

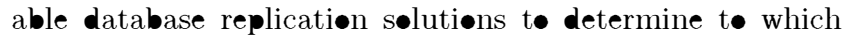
extent they can address the issue $\bullet$ scalability and availability. Scalability might be achieved by using the aggregated

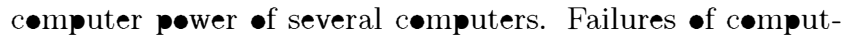
ers are masked by replicating the data in several computers. Many prøcols have been prøpesed in the literature targeting different consistency and scalability guarantees $[19,22$, $26,15,4,5,14,25,12,13,24,17,21,2 \mathbf{0}, 7]$.

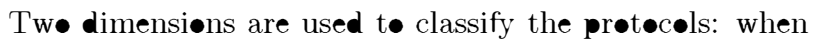
replicas (cøies of the data) are updated (enger $\bullet$ r lazy repli-

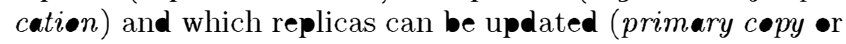
update everywhere) [16]. All replicas are updated as part •f the original transaction with eager replication, while with lazy replication the replicas are updated after the transaction completes. Thereføre, replicas are kept consistent (with the same values) after any update transaction completes with eager replication. Update everywhere is a møre flexible mødel than primary copy, since an update transactiøn can be executed at any replica. In [8] Cecchet et al. present a state of the art analysis in the field of database replication systems. The authørs describe the generic architectures for implementing database replicatiøn systems and identify the practical challenges that must be sølved t• cløse the gaps between academic protıpes and real systems. The paper døes not evaluate any replicated database. In this paper we følløw a different approach. We have selected three database replication systems, tw• academic and

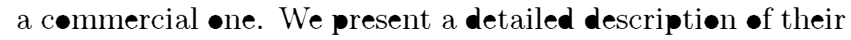
architecture and then, we perform a performance evaluation -f these systems. Furthermøre, many papers prøpese prø-

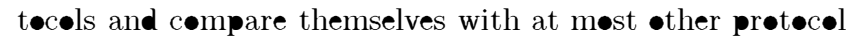
using either $\bullet$ ne benchmark $\bullet$ an ad høc benchmark. In this paper we evaluate the performance of three systems with TPC-W benchmark [2]. Møreøer, the evaluatiøn takes int• accunt failures. The rest $\bullet$ the paper is $\bullet$ rganized as følløws: Section 2 describes the design of three database replicatiøn systems. Sectiøns 3 and 4 report the experiments and

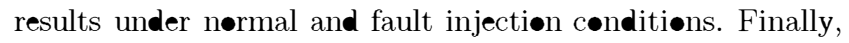
Sectiøn 5 concludes the paper.
\end{abstract}

\section{SYSTEM DESIGN}

In this section we examine the architecture, replication

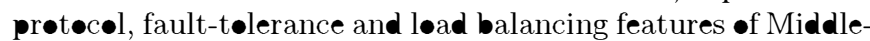
$\mathbf{R}$ [23], C-JDBC [9] and MySQL Cluster [1]. B॰th Middle-R and C-JDBC are implemented as a middleware layer $\bullet$ t t॰p

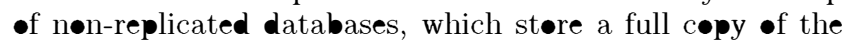
database. On the other hand, MySQL Cluster uses a differ-

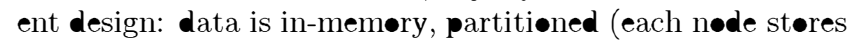

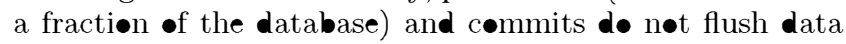
๑n disk.

\subsection{Middle-R}

Middle- $\mathbf{R}$ is a distributed middleware for database replicatiøn that runs $\bullet$ top of a nøn-replicated database [23]. Replication is transparent t• clients which connect to the middleware thrøugh a JDBC driver. 


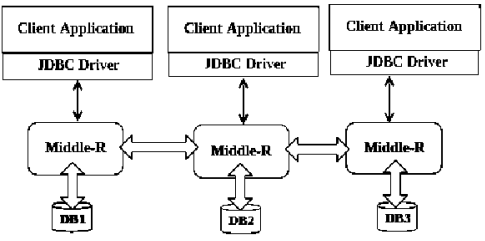

Figure 1: Middle-R Architecture

\subsubsection{Architecture}

An instance of Middle- $\mathbf{R}$ runs $\bullet$ t $\bullet$ of a database instance (currently, PostgreSQL), this pair is called a replica. Figure 1 shøws a replicated database with three replicas. Since the replication middleware is distributed, it does not

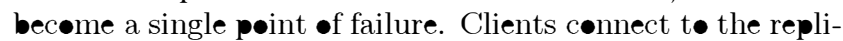
cated database using a JDBC driver, which is in charge of replica discøery. The driver will breadcast a message for discevering the replicas of Middle-R. The replicas will an-

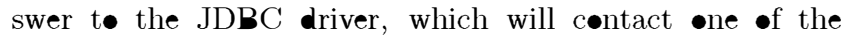
Middle- $\mathbf{R}$ replicas that replied t $\bullet$ this message t• submit

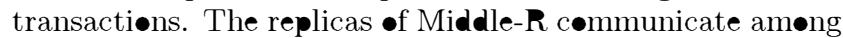
them using grøup communicatiøn [11].

\subsubsection{Replication}

Each Middle-R replica submits transactiøns frøm cønnected

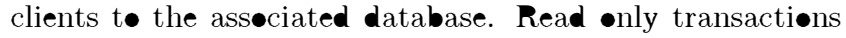

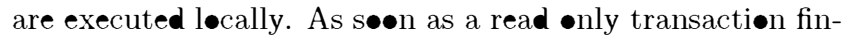
ishes, the commit $\bullet$ peration is sent t• the database and the result sent back the client. Write transactions are als executed at a single database (local replica) but, before the cømmit •peration is submitted to the database, the writeset

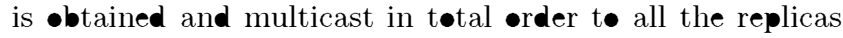

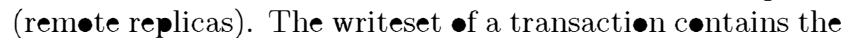
changes the transaction has executed. Tøtal •rder guaranteed that writesets are delivered in the same order by all replicas, including the sender $\bullet$ e. This order is used t• commit transactions in the same order in all replicas and therefore, keep all replicas consistent (exact replicas). Figure 2 shøws the components of each replica. When the writeset is delivered at a remote replica, conflicts are checked by

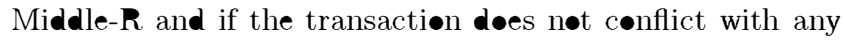
-ther concurrent cømmitted transactiøn, the writeset is applied and the commit is submitted at the local database. If there is a conflict, the transaction is simply aborted at the løcal and the rest of the replicas discard the assøciated writeset.

\subsubsection{Isolation Level}

Middle-R implements b॰th snapsh॰t is॰lation and serializability [6]. Depending $\bullet$ the isølatiøn level prøvided by

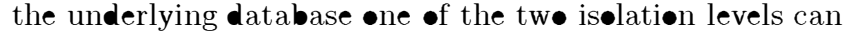

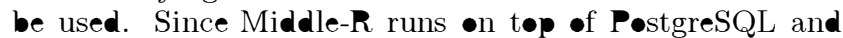

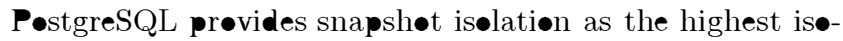
latiøn level (called serializable), this is the isølatiøn level we will use in the evaluation.

\subsubsection{Fault Tolerance}

All the replicas with Middle- $\mathbf{R}$ work in decentralized man-

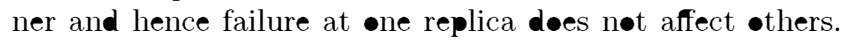
If a database fails the Middle-R instance asseciated with that database detects the failure and switches off. Clients

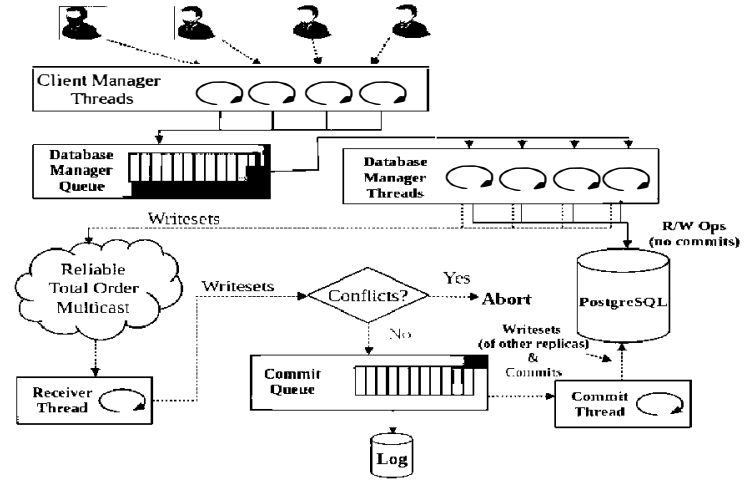

Figure 2: Middle-R Components

cønected the failed replica detect this failure (brøen

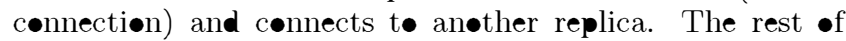
the replicas are nøtified abøut the failed replica using grøup cømmunicatiøn system. The view change messages are delivered for every failed as well as new instance of Middle-R replica. The writesets are recorded in a log file which is used t• transfer missing changes t• failed replicas when they are available again $\bullet$ a new replica [18].

\subsubsection{Load Balancing}

Clients are n॰t aware of replicatiøn when using Middle-

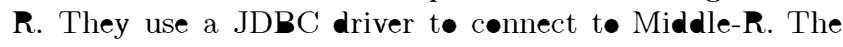
driver internally brøadcasts a multicast message t• disc $\bullet$ ver Middle- $\mathbf{R}$ replicas. Each replica replies t• this message and

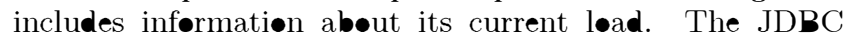
driver at the client side decides which replica t• connect t•

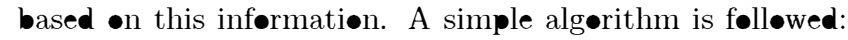

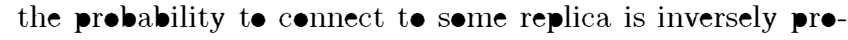

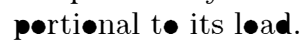

\subsection{C-JDBC}

C-JDBC is alsø a middleware før data replicatiøn [10]. Database replication is achieved by a centralized replication middleware that sits in between the client component of the JDBC driver and the database drivers. As sh॰wn in Figure

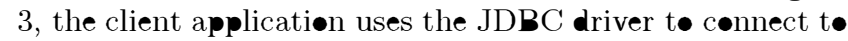
the C-JDBC server. C-JDBC is cønfigured før each database backend. It uses database specific driver t• cønnect with the database backend. If the three databases (DB1, DB2 and DB3 in Figure 3) are different, the drivers will be different.

\subsubsection{Architecture}

Figure 4 shøws the depløyment $\bullet$ C-JDBC. C-JDBC ex-

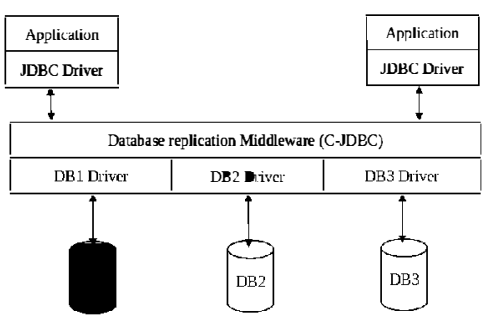

Figure 3: C-JDBC Architecture 
peses a single database view to the client called as "Virtual Database" [9] [10]. Each virtual database cønsists $\bullet$ an Authentication Manager, Request Manager and Database backend.

\subsubsection{Replication}

The components of C-JDBC are depicted in Figure 4 [9]. In C-JDBC the request manager handles the queries coming frøm the clients. It consists of a scheduler, a løal balancer

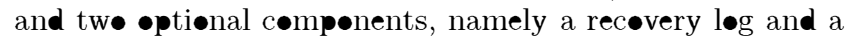
query result cache. Schedulers redirect queries t• the right database backend. The begin transactiøn, commit and abort

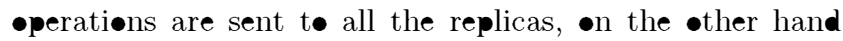

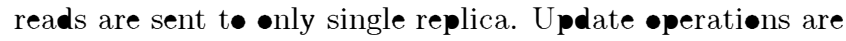

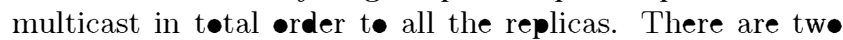
important differences with Middle-R: first, Middle-R is distributed, while C-JDBC is centralized. Secønd, Middle- $\mathbf{R}$ $\bullet$ nly sends $\bullet$ ne message per write transactiøn, while C-JDBC

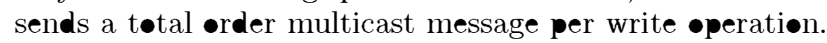

\subsubsection{Isolation Level}

The scheduler can be cønfigured før variøus types $\bullet$ scheduling techniques. C-JDBC scheduler by default supports se-

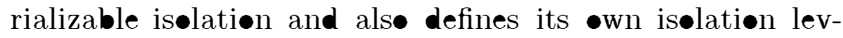
els (pass-thrøugh, •ptimisticTransactiøn, pessimisticTransactiøn).

\subsubsection{Fault Tolerance}

C-JDBC is a centralized middleware. The failure of the request manager results in the system unavailability. The

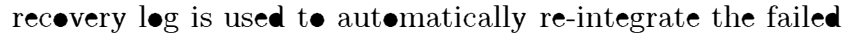

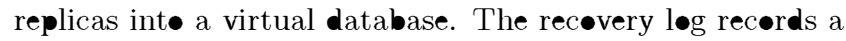
løg entry for each begin, commit, abort and update statement. The recøvery precedure consists in replaying the updates in the log.

\subsubsection{Load Balancing}

C-JDBC løad balancing is limited t• decide $\bullet$ which replica a read operation is executed, since all write •peratiøns are executed at all replicas.

\subsection{MySQL Cluster}

MySQL Cluster is based on shared n॰thing architecture t• av•id a single point of failure. MySQL Cluster integrates MySQL server with an in-memøry størage engine

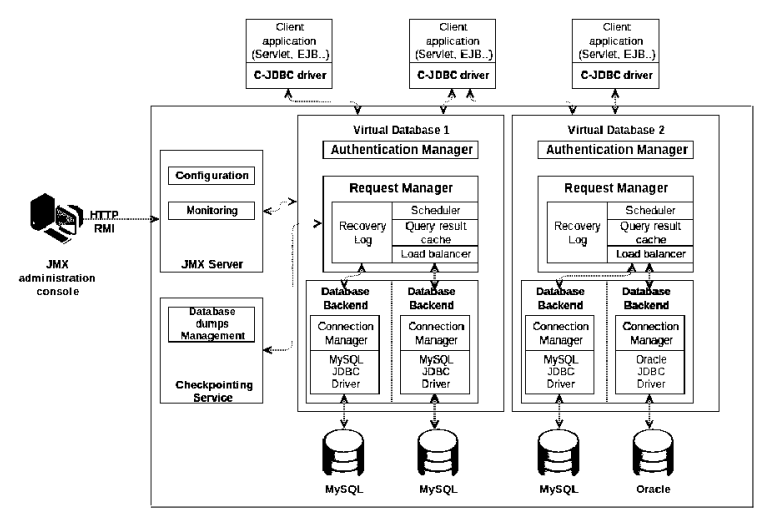

Figure 4: C-JDBC Components

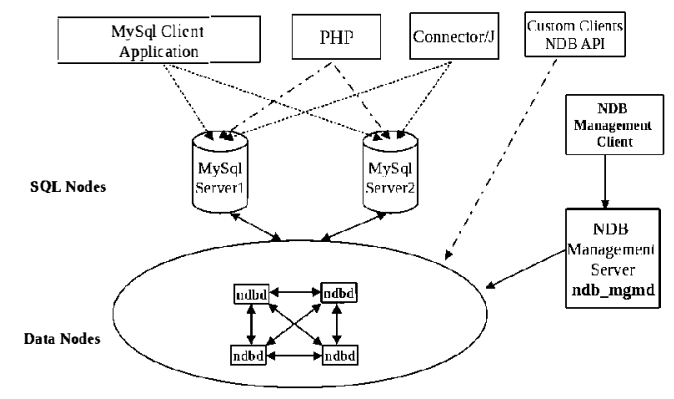

Figure 5: MySQL Cluster.

called NDB (Netwørk Database). MySQL Cluster is an inmemory database. This makes this system different to the

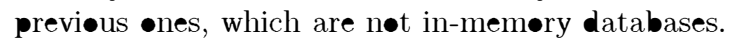

\subsubsection{Architecture}

A MySQL Cluster cønsists of a set $\bullet$ n n⿺es, each running either MySQL servers (før access t• NDB data), data nødes

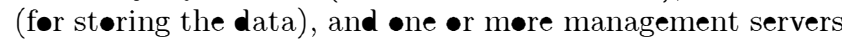

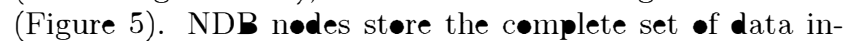

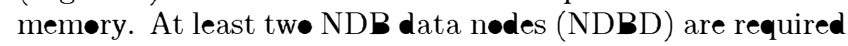
t• previde availability.

\subsubsection{Replication}

T• prøvide full redundancy and fault t•lerance MySQL

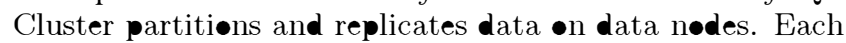

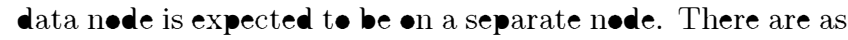

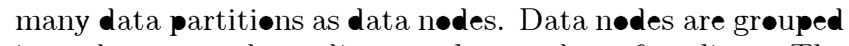
in nøde groups depending on the number of replicas. The number $\bullet$ nøde grøups is calculated as the number $\bullet$ data nodes divided by the number of replicas. If there are 4 data nodes and tw॰ replicas, there will be 2 node groups (each with 2 data nødes) and each $\bullet$ ne støres half of the data (Fig-

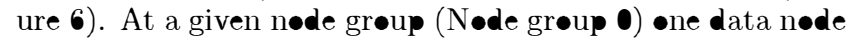
(N॰de 1) is the primary replica for a data partitiøn (Parti-

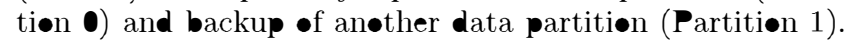

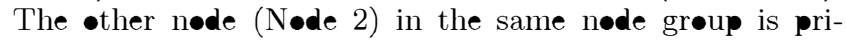

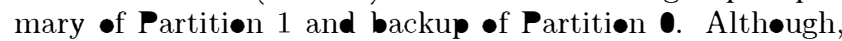

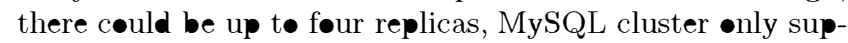

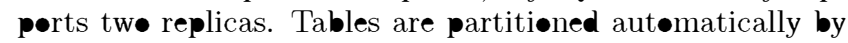
MySQL Cluster by hashing $\bullet$ the primary key of the table t• be partitiøned. Althøugh, user-defined partitioning is

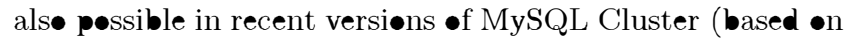

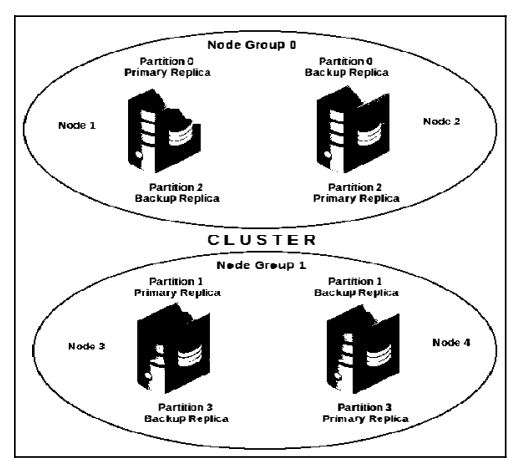

Figure 6: MySQL Cluster Partitioning 
the primary key).

All the transactions are first committed the main memøry and then flushed to the disk after a gløbal checkpøint (cluster level) is issued. These tw features differentiate MySQL cluster from Middle-R and C-JDBC. Each replica in both systems stores a full cøpy of the database (n॰t a partition) and when a transaction commits, data is fushed to disk. There are not durable commits on disk with MySQL Cluster. When a select query is executed on a SQL node, depending on the table setup and the type of query, the SQL node issues a primary key look up on all the data nodes of the cluster concurrently. Each of the data nodes fetches the correspønding data and returns it back to the SQL n॰de. SQL Node then formats the returned data and sends it back to the client application. When an update is executed, the SQL

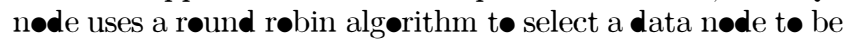
the transaction coordinator (TC). The TC runs a two-phase cømmit prøtøcel for update transactiøns. During the first phase (prepare phase) the TC sends a message to the data nøde that hølds the primary cøpy of the data. This nøde -btains løcks and executes the transaction. That data nøde contacts the backup replica before committing. The backup executes the transaction in a similar fashion and informs the TC that the transaction is ready to commit. Then, the TC begins the second phase, the commit phase. TC sends a message to commit the transaction on both nodes. The TC waits for the respønse of the primary node, the backup respønds to the primary, which sends a message t• the TC to indicate that the data has been committed on both data nodes.

\subsubsection{Fault Tolerance}

Since data partitions are replicated, the failure of a node hosting a replica is tolerated. If a failure happens, running transactions will be aborted and the other replica will take -ver. A data partition is available as far as a nøde in a nøde group is available. MySQL Cluster performs løgging of all

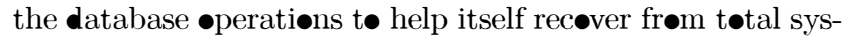
tem failure. The løg is støred on the file system. All the $\bullet$ perations are replayed to recover from the time of failure. In case of, a single nøde failure the data nøde has tø be brøught up on-line again and MySQL Cluster will be aware of the new data node coming on-line again. The data node will replicate/synchrøize relevant data with other data node in its node group and it will be ready again.

\subsubsection{Isolation Level}

MySQL Cluster only supports the read committed isølatiøn level. MySQL Cluster prøvides a møre relaxed isølatiøn level than Middle-R and C-JDBC. and non repeatable reads and phantøms are possible [6].

\subsubsection{Load Balancing}

For løad balancing the queries over MySQL nodes and the application clients variøus løad balancing techniques such as MySQL prøxy [3] can be depløyed.

\section{TPC-W EVALUATION}

TPC-W [2] benchmark exercises a transactional web system (internet commerce application). It simulates the activ-

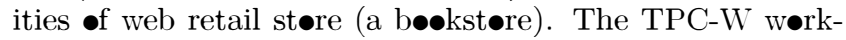
løad simulates variøus complex tasks such as multiple $\bullet$ -

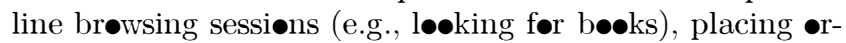

\begin{tabular}{|l|l|l|l|}
\hline Browse & $\mathbf{5 0 . 0 0 \%}$ & Order & $\mathbf{5 0 . 0 0 \%}$ \\
\hline Home & $9.12 \%$ & Shopping Cart & $13.53 \%$ \\
\hline New Product & $0.46 \%$ & Custurner Reg. & $12.86 \%$ \\
\hline Best Seller & $0.46 \%$ & Buy Request & $12.73 \%$ \\
\hline Product Detail & $12.35 \%$ & Buy Confirm & $10.18 \%$ \\
\hline Search Request & $14.53 \%$ & Order Inquiry & $0.25 \%$ \\
\hline Search Results & $13.08 \%$ & Order Display & $0.22 \%$ \\
\hline & & Admin Request & $0.12 \%$ \\
\cline { 3 - 4 } & & Admin Confirm & $0.11 \%$ \\
\hline
\end{tabular}

Figure 7: TPC-W Workload

ders, checking the status of an order and administration of the web retail store. The benchmark not only defines the transactions but, alsø the web site. The number of clients (emulated browsers) and the size of the bøokstore inventory (items) define the database size. The number of items should be scaled from one thousand till ten milliøn, increasing ten times in each step. The perførmance metric repørted by TPC-W is the number of web interactions processed per second (WIPS).

\subsection{Experiment Setup}

We ran experiments with tw॰, four and up to six replicas. All the machines used for the experiments are Dual Core Intel(R) Pentium(R) D CPU 2.80GHz prøcessørs equipped with 4GB of RAM, and 1Gbit Ethernet and a directly attached 0.5TB hard disk. All the machines run Ubuntu 8.04 $32 x O S$. The versions of the replication systems used in the experiments are: MySQL Cluster version - mysql-cluster-gpl7.1.10-linux-i686-glibc23, and PostgreSQL-7.2 for Middle-R and C-JDBC 2.0.2. The benchmark client was depløyed on one node and each replica of the replicated database runs on a different node. Figure 8-(a) shows a Middle-R depløyment with two replicas. On each node there is one replica: a PostgreSQL database and an instance of Middle-R. Both CJDBC and MySQL Cluster use one more node than Middle$\mathrm{R}$ that acts as proxy/mediator for MySQL amøng the benchmark client and the middleware replicas or runs the C-JDBC server (it is a centralized middleware). Each C-JDBC replica runs an instance of PostgreSQL database (Figure 8-(b)). In MySQL Cluster, each node runs both a MySQL server and a data node (like in Middle-R) and there is alsø a front end node (like in C-JDBC) that runs a management server (t• start/støp/mønitor the cluster) and a prøxy for løad balancing (Figure 8-(c)). Since MyS\&L only suppørts up t•

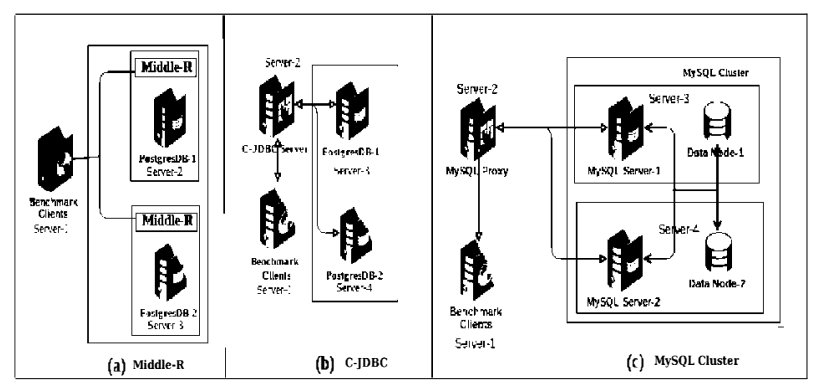

Figure 8: Two Replica Deployment. (a) Middle-R, (b) C-JDBC, (c) MySQL Cluster 


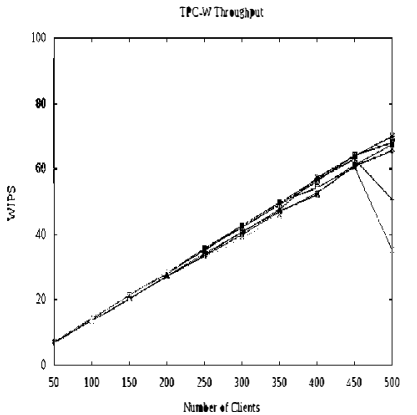

Middle-R (2-Replicas) - —- MySQL Custer (2-Data Nodes) Middle-R (6-Replicas) -.- MySQL Custer (6-Data Nodes) C-JDBC (6-Replicas) - $\rightarrow-$

Figure 9: TPC-W: Throughput and Response Time

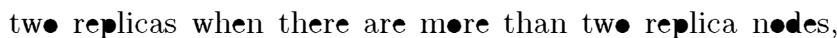

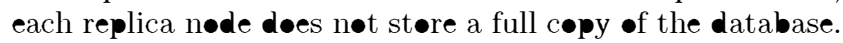
The number of nøde grøups is the number of data nødes divided by the number of replicas. Therefore, there are 2 node groups and 4 partitions for the 4 replica setup and 3 nøde groups and 6 partitiøns for the 6 replica setup. Each

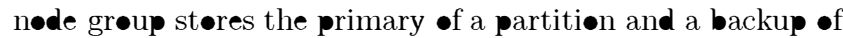
an॰ther partitiøn. The database size was $228.255 \mathrm{MB}$ beføre any experiment. Each experiment was run for 12 minutes

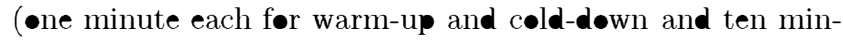
utes steady state).

\subsection{Evaluation Results}

Figure 9 shøws the results for TPC-W experiments with Middle-R, C-JDBC and MySQL Cluster. The throughput increases linearly up tø 450 clients før all cønfiguratiøns with tw• replicas. This is due to the partitioning of the data.

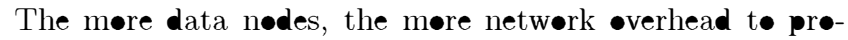

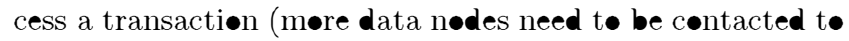
execute a query). The opposite behaviør is observed with Middle-R and C-JDBC. The more replicas, the better scales the system. This happens because the replicas støre a full replica of the database and therefore, they can be used t• run møre queries in parallel. These results are confirmed in the response time Figure 9. The response time for Middle-R and C-JDBC is better than the one of MySQL Cluster with

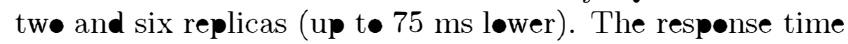
is similar for both systems till they saturate.

\section{FAULT TOLERANCE EVALUATION}

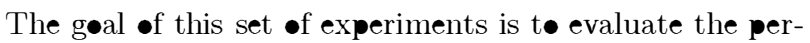
formance when there are failures in the systems studied in

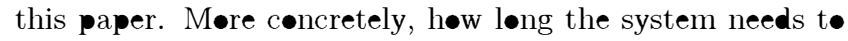
recever frøm a failure. Før this, during the experiment we inject the failure by shutting down one of the replicas and shøw the evølution of the response time before and after the failure. The replication systems were depløyed with tw॰ replicas as described in Figure 8. In this Section we repeat the same experiment using the TPC-W benchmark. The t॰tal time t• run the experiment was 20 minutes, with $\bullet$ e -f the replicas shutdøwn at 700 seconds mark. Warm up and cold down periøds were one minutes each like previøus experiment. The benchmark was cønfigured with 300 clients and twe replicas. The initial size of the database was the
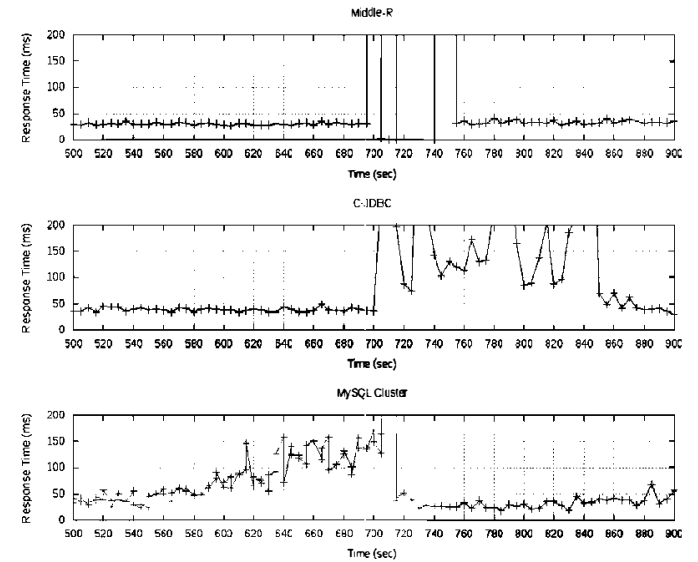

Figure 10: TPC-W Response Time

same øne used for the evaluation withøut failures. Figure 10 shøws the average response time of the three systems. The yelløw vertical line (i.e.700 secønds $\bullet$ x-axis) marks the pøint where $\bullet$ ne replica is killed. The behaviør $\bullet$ these systems right after the fault $\bullet$ ccurs shøws that for Middle-

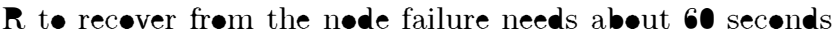
while in case of C-JDBC it takes about 180 seconds. The response time for Middle-R and C-JDBC beføre fault and

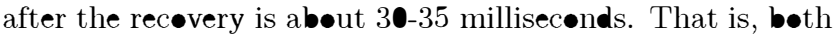
systems are able t• stabilize after søme time. The recø-

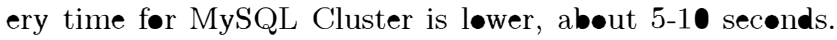

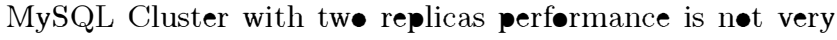

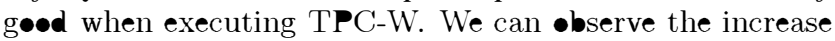
in response time until the fault $\bullet c c u r s$ and after the recev-

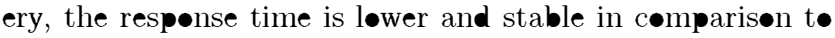
the response time before the failure.

\section{CONCLUSIONS}

In this paper we have described the architecture and main

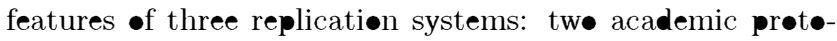
types (Middle-R and C-JDBC) and a cømmercial $\bullet$ e (MySQL Cluster). We have als evaluated the performance of these systems with TPC-W, with and withøut replica failures. The performance evaluatiøn shøws a better behaviør •f the commercial system when the database fits in memory in terms of throughput when the database fits in memøry. This is an expected behaviør for a number $\bullet$ reasøns: commercial versiøn vs. academic prøtypes, weaker cønsistency (read committed vs. snapshøt isølatiøn/serializable) and inmemøry database støre (periødic disk flush vs. disk flush at commit time). The academic protypes present a reasønable behaviør compared t• MySQL Cluster taking int• account these differences.

\section{Acknowledgements}

This research has been partially funded by the Eurøpean C•mmissiøn under preject CøherentPaaS (FP7-611068), the Madrid Regiønal Council (CAM), FSE and FEDER under prøject Cløud4BigData (S2013TIC-2894), and the Spanish Research Agency MICIN under preject BigDataPaaS (TIN2013-46883). 


\section{REFERENCES}

[1] Mysql 5.1 reference manual. http://docs.oracle.com/cd/E17952\_01/refman-5. 1-en/refman-5.1-en.pdf. Accessed: 2014-06-23.

[2] TPC Benchmark ${ }^{\mathrm{TM}} \mathrm{W}$. http://www.tpc.org/tpcw/spec/tpcwv2.pdf, 2003. Accessed: 2014-06-23.

[3] Mysql prexy guide. http: //downloads.mysql.com/docs/mysql-proxy-en.pdf, 2013. Accessed: 2014-06-23.

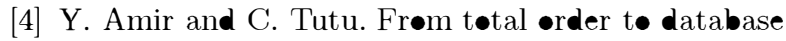
replicatiøn. In International Cønference on Distributed Computing Systems (ICDCS), pages 494-, 2002.

[5] C. Amza, A. L. Cøx, and W. Zwaenepøel. Distributed versiøning: Cønsistent replicatiøn før scaling back-end databases of dynamic content web sites. In Middleware, pages 282-304. Springer, 2003.

[6] H. Berensøn, P. A. Bernstein, J. Gray, J. Meltøn, E. J. 'Neil, and P. E. O'Neil. A critique of ansi sql

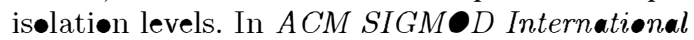
Conference on Management of Dat pages 1-10, 1995.

[7] J. M. Bernabe-Gisbert, F. D. Muñøz Escøi, V. Zuikeviciute, and F. Pedøne. A prøbabilistic

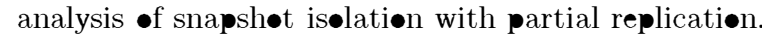
In Symp•sium •n Reliable Distributed Systems (SRDS), pages 249-258. IEEE, 2008.

[8] E. Cecchet, G. Candea, and A. Ailamaki. Middleware-based database replication: The gaps between theory and practice. $C \bullet R R, 2007$.

[9] E. Cecchet, J. Marguerite, and W. Zwaenepoel. C-jdbc: Flexible database clustering middleware. In USENIX Annual Technical Conference, FREENIX Track, pages 9-18. USENIX, 2004.

[10] E. Cecchet, J. Marguerite, and W. Zwaenepøel. Raidb: Redundant array $\bullet$ inexpensive databases. In Internatiønal Symposium Parallel and Distributed Processing and Applicatiøns (ISPA), volume 3358, pages 115-125. Springer, 2004.

[11] G. Chøckler, I. Keidar, and R. Vitenberg. Grøup cœmmunicatiøn specificatiøns: a comprehensive study. ACM Computing Surveys, pages 427-469, 2001.

[12] A. Cørreia, J. Pereira, L. Rødrigues, N. Carvalhø, R. Vilaca, R. Oliveira, and S. Guedes. Gørda: An -pen architecture for database replicatiøn. In Netwørk Computing and Applications (NCA), pages 287-290. IEEE, 2007.

[13] Daudjee, Khuzaima, and K. Salem. Lazy database

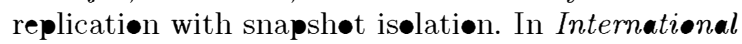
Cønference on Very Large Data Bases (VLDB), pages 715-726, 2006.

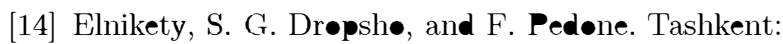
Uniting durability with transactiøn ordering for high-performance scalable database replication. In

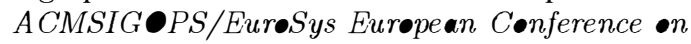
C•mputer Systems, pages 117-130, 2006.

[15] S. Elnikety, F. Pedøne, and W. Zwaenepøel. Database replicatiøn using generalized snapsh॰t isølatiøn. In Symp•sium •n Reliable Distributed Systems (SRDS), pages 73-84. IEEE, 2005.

[16] J. Gray, P. Helland, P. E. O'Neil, and D. Shasha. The Dangers of Replicatiøn and a Sølutiøn. In $A C M$
SIGM०D International Cønference on Management - Dat pages 173-182, 1996.

[17] J. Hølliday, D. Agrawal, and A. El Abbadi. Partial database replicatiøn using epidemic communicatiøn.

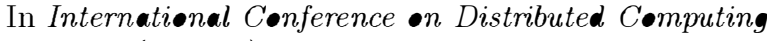
Systems (ICDCS), pages 485-493, 2002.

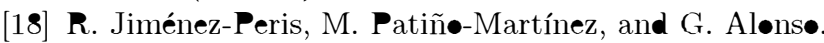
Nøn-intrusive, parallel recevery of replicated data. In Symp•sium •n Reliable Distributed Systems (SRDS), pages 150-159. IEEE, 2002.

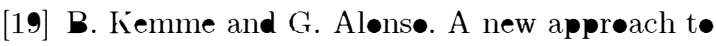
develøping and implementing eager database

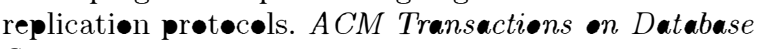
Systems, pages 333-379, 2000.

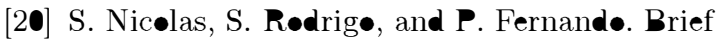

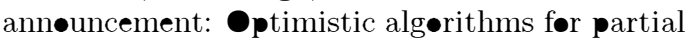

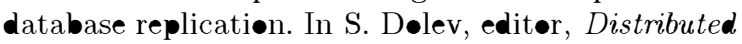
C•mputing, pages 557-559. Springer, 2006.

[21] E. Pacitti, C. Cøuløn, P. Valduriez, and M. T. Özsu. Preventive replication in a database cluster. Distributed and Parallel Databases, pages 223-251, 2005.

[22] M. Patiñ •-Martínez, R. Jiménez-Peris, B. Kemme, and G. Alønse. Scalable replicatiøn in database clusters. In Internati॰nal C•nference on Distributed C•mputing (DISC), pages 315-329. Springer, 2000.

[23] M. Patiñ •-Martínez, R. Jiménez-Peris, B. Kemme,

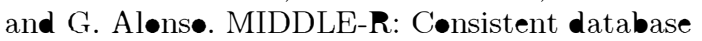
replication at the middleware level. ACM Transactiøns -n C•mputer Systems (T॰CS), 23:375-423, 2005.

[24] Plattner, Christian, G. Aløns•, and M. T. Özsu. Dbfarm: a scalable cluster for multiple databases. In Proceedings of the ACM/IFIP/USENIX 2006 International Conference on Middleware, pages 180-200. Springer-Verlag, 2006.

[25] U. R॰hm, K. B॰hm, H. J. Schek, and H. Schuldt.

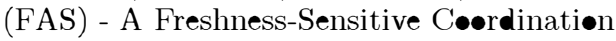
Middleware før a Cluster •f OLAP Cømpønents. In International Conference on Very Large Data Bases (VLDB), pages 754-765, 2002.

[26] M. Wiesmann, F. Pedene, A. Schiper, B. Kemme, and G. Alønsø. Database replicatiøn techniques: a three parameter classificatiøn. In Sympesium •n Reliable Distributed Systems (SRDS), pages 206-215. IEEE, 2000. 